\title{
Stress factors in the work of nurses
}

V. Kozon, E. Zacharova

Original Articles

St. Elizabeth University of Health and Social Work in Bratislava, Slovak Republic

\section{Correspondence to:}

Vienna General Hospital Vienna, Währinger Gürtel 18-20, 1090 Wien, Austria;

eva.zacharova@seznam.cz; vlastimil.kozon@univie.ac.at

Submitted: 2.5 .2016

Revised: 29.7.2016

Accepted: 13.8 .2016

\section{Reviewers:}

V. N. Wanjala

Catholic university of Eastern Africa, Nairobi, Kenya

M. Kopacikova

Faculty of Health, Catholic University in Ruzomberok, Slovakia

\section{Keywords:}

Stress. Strain. Nurse. Burnout syndrome. Stress factors.

CSWHI 2016; 7(2): 105-115 @ 2016 Clinical Social Work and Health Intervention

\section{Abstract:}

Being a nurse is amongst one of the toughest professions. It is a profession in which the nurse will be in contact with different kinds of stress factors. There are often encounters with death, suffering, as well as dying and terminally ill patients. Nurses must be able to communicate with patients who react differently to illness and hospitalization and those patients who can even cause conflicts. In addition to the direct workloads regarding this range of problems there are also bad relationships in the workplace and difficulties in everyday life. There is also the need for continuous training and learning of new skills. The influence of all these factors can lead the nurse into difficult situations in life - such as excessive stress. The aim of this research was to determine stress factors that influence the work of nurses in outpatient and inpatient wards. 


\section{Introduction}

The word stress has been accepted into the Czech language from the English language. In Czech the translation means distress, inconvenience, pressure. In recent years, there has been a growing public interest and professional awareness about stress and its consequences. This is a reaction to the fact that stress has become an integral part of human life in the 21 st century. In recent years the actual understanding of the concept of stress has undergone a significant evolution. It has transferred from the biological level to the psychosocial level. In everyday speech we often refer to everything as stress that somehow pushes us, overloads or strains us, as well as things which are uncomfortable. It accompanies us from birth to old age. It belongs to the natural manifestations of life, if it is reasonable, and does not last a long period. In the modern world a disproportionate amount of stress is a major health risk, as shown by the results of a series of global investigations and contributes to, among other things, the ever-growing intensity of performance, the speed of work and time pressure. People increasingly evaluate their work as mentally demanding and performed at a higher pace of work, rather than as physically strenuous. Nurses working in a health care facility must overcome all the difficulties that occur during their service. In addition to stressful situations there can be poor working conditions, work overload, extraordinary responsibility, daily contact with dying or seriously ill patients, but also the circumstances in relation to interpersonal relationships, financial rewards, etc. $(1,2)$.

\section{Goals}

The goals of the research were to determine stress factors that influence the work of nurses in outpatient and inpatient wards.
Partial goals

1. Determine the workload of nurses in outpatient and inpatient wards.

2. Determine labour relations and mutual cooperation of nurses at work in the outpatient and inpatient wards.

3. Determine the psychological stress of nurses in communications with the patient and their family in outpatient and inpatient wards.

4. Determine whether there are differences in the workload between outpatient and inpatient wards.

\section{Patients and Survey Methods}

The questionnaire survey was conducted in the year 2015 on randomly selected hospitals in the Moravian-Silesian Region. The research involved 135 nurses from outpatient and inpatient wards. The study included various departments - internal, oncological, urological, neurological and gynaecological.

There were 150 questionnaire surveys distributed of which 137 questionnaires surveys were returned. In other words a $91 \%$ success return rate. There were 2 questionnaire surveys excluded from the overall evaluation as they were incompletely filled out. Data collection was preceeded by a pilot study on the basis of which it was verified that the questionnaire survey was comprehensible for the participants and that individual questions were understood correctly. A quantitative method was chosen for information gathering as well as a questionnaire survey. The questionnaire survey was voluntary and anonymous. The questionnaire survey included a total of 30 questions, including 5 demographic, of which 24 were closed and one open. The questions were focused on the area of the workload of nurses, labour relations and collaboration in the workplace, as well as to the psychological stress of nurses taking care of patients. 
It was monitored by subjective evaluation of the intensity of work and the relationship of respondents to the profession. The last question was open, where the respondents expressed their opinion. When processing the results of the research, 135 correctly and completely filled in questionnaire surveys were used, which was taken as a $100 \%$ participation rate. The data obtained was processed using Microsoft Excel.

\section{Results and Discussion}

The aim of the research was to determine, from the questionnaire surveys, what the stress factors that influence the work of nurses in outpatient and inpatient wards were. Based on the survey results the following facts were revealed. The research involved a total of 135 respondents of which 95\% were women and 5\% were men. This means that for the outpatient wards, $44 \%$ were women and 1\% were men. And for the inpatient wards, $51 \%$ were women and $4 \%$ were men. The largest overall group of those nurses questioned, 29\%, were in the age category of 31-40 years. 28\% were in the category of $41-50$ years. $25 \%$ were in the category of 20-30 years. And 18\% were in the category of 51 or more years. For the inpatient wards, the largest representation of nurses were in the age group 2030 years $(43 \%)$, followed by the age group $41-50$ years $(24 \%)$, then the age group 31 40 years $(18 \%)$ and the least representation of nurses were in the age group of over 51 years $(15 \%)$. For the outpatient wards, the largest representation of nurses were in the age group of 31-40 years (43\%), followed by the age group $41-50$ years $(31 \%)$, then the age group of over 51 years $(23 \%)$ and the least representation of nurses were in the age group of $20-30$ years (3\%).

The issue of labour relations is constantly monitored worldwide. The research monitored the atmosphere of the work- place, including relationships between general nurses and doctors, and whether there are general nurses who do specialized tasks that do not fall within their competence. The largest group of nurses working in outpatient wards considered the relationships in the workplace as good (51\%), $20 \%$ of respondents stated very good, $23 \%$ of respondents evaluated interpersonal relations as bad, and $6 \%$ of nurses said relations at their workplace were very bad. For inpatient wards, $40 \%$ of respondents cited it as a good relationship, further $45 \%$ as poor and $8 \%$ very poor. On the contrary, $7 \%$ of nurses felt that working relations were very good (table 1).

Under the relationship with their superior, it was found that $49 \%$ of nurses have a good relationship with their superiors and $18 \%$ of respondents stated it as very good. A group of $21 \%$ of nurses assessed their access to superiors as poor and $12 \%$ of nurses assessed it as very bad. With regards to the attitude of senior nurses to subordinates in inpatient wards, $47 \%$ of respondents said they were bad and $10 \%$ said it was very bad. But $38 \%$ of nurses evaluated the relationship as good and $5 \%$ as very good (table 2).

Research results by Bártlova in 2006, which were carried out on the basis of interviews with 348 nurses across the country, showed similar results. Satisfaction prevails extensively among general nurses in the workplace. Overall, nurses employed in the offices cited a favourable working atmosphere. This is understandable because in these workplaces the nurses operate in close contact with the doctor. Additionally, the number of workers in the workplace is small and labour conflicts are less common than in workplaces with large numbers of employees. Features of the workplace also have a strong influence on the evaluation of the workplace atmosphere (3). Křivohlavý (6) also found in his 
survey that when he asked nurses what the source of their strength and joy in the job was, he frequently received answers such as a good team, good and unbeatable atmosphere in the workplace, cooperation of colleagues in the workplace, and superiors who valued them.

At present, we can say that conditions for new insights into the role of doctors and nurses and other quality of their professional conduct are being created. Cooperation between doctors and nurses should take place at a level of equal relations. In this research, however, $27 \%$ of nurses on inpatient wards evaluate cooperation with a doctor as good, with $11 \%$ as very good. The largest group of $47 \%$ believe that the mutual cooperation is poor and $15 \%$ of respondents consider it as very bad. In the evaluation of cooperation of doctors and nurses in surgeries and outpatient examinations, $45 \%$ of nurses stated it as good, $16 \%$ as very good, $28 \%$ as poor, and $11 \%$ consider it as very poor (table 3 ).

On the question regarding commendations from superiors, $36 \%$ of outpatient nurses said that they sometimes receive support and praise, $23 \%$ stated that they often receive it, $15 \%$ stated very often, and $26 \%$ of respondents stated that they never receive it. For inpatient nurses, 54\% of respondents stated occasional commendations, $11 \%$ stated as receiving it often, 3\% as very often. But a group of $32 \%$ of nurses did not feel like they received any support in their jobs from senior nurses (table 4). This situation is very alarming. According to the survey findings by Vévoda (9), he stated that this factor is significantly important for employees, as the source may not only be a superior but also a professional colleague, client - patient. Vévoda feels that nurses who do not work in continuous operation are often commended with praise and support. The identical result was also noted by Bártlová who found that the happiest nurses are employed in outpatient facilities. Their work with their superiors is the most valued. General nurses often lack a sense of security, motivation and the appropriate valuation of work in relation to the senior nurses.

An area that largely affects the status of nurses in multidisciplinary teams and which also has a significant influence on the relationship of doctors and nurses is the issue of competence. The competence of nurses in the Czech Republic is legally regulated by Act no. 96/2004 Coll. which deals with the conditions for acquisition and recognition of qualifications for exercising paramedical professions and for carrying out the activity of providing health care. Regarding tasks that do not fall within the competence of nurses, the results were $46 \%$ for inpatient nurses and 51\% for outpatient nurses. The second largest group stated that it is very often delegating responsibilities from others. This was 35\% for outpatient nurses and $47 \%$ for inpatient nurses (table 5).

In a 2010 survey entitled "Transfer of competencies between the doctor and nurse" by the authors Bártlová and Hajduchová, they state that nurses are quite often entrusted with the tasks falling within the competence of someone else and that do not match their qualifications (4). This is a delegation of special tasks from doctors or by the senior sister in the execution of work by paramedical personnel. From the analysis the authors revealed that most nurses are entrusted with tasks outside of their competence in administrative natures, i.e. acts related with the management of documents, creating requisitions, compiling reports on health insurance, processing statistical questionnaires, creating prescriptions, providing information, securing informed consent, etc. Inpatient nurses may frequently reject to perform these tasks however nurses working in 
clinics may reject these tasks significantly less frequently. There is a greater tendency to reject tasks outside the competence by nurses working in surgical specialties, by nurses with a higher education (master's degree), and by nurses with long work experience and stationed in an office.

Surprising was the question of education of nurses. Obtaining vocational education forms the foundation which influences the further position of nurses in a multidisciplinary team and in the company (8). The possibility of receiving further vocational training was available to $21 \%$ of respondents in outpatient wards, with inpatient wards showing $25 \%$. Nurses who frequently chose the answer "yes, but I'm not interested" amounted to $65 \%$ for inpatient wards and $54 \%$ for outpatient wards. $23 \%$ of nurses from outpatient wards and $5 \%$ of nurses from inpatient wards stated that they do not have the possibility to take part in further training nor are they interested in it.

The majority of the respondents from this research believe that nurses do not have sufficient social prestige. Only a tiny percentage of respondents evaluated the situation positively (table 7). According to the authors Škrla, Škrlová (8), a permanent change in the image of nursing must start with the education in medical schools, where students are guided with a professional image and provided with the understanding that the nursing profession has a character, and as such it is not just a job but a good career.

The amount of administrative work often burdened on the nurses in the outpatient wards is $38 \%$ and for the inpatient wards is $24 \%$. Nurses who stated being burdened as "very often" accounted for $31 \%$ for outpatient wards, and $60 \%$ for the inpatient wards. The word "sometimes" occurred for $28 \%$ of outpatient nurses and for $12 \%$ for inpatient nurses (table 8 ). The identical findings were by Bártlová who revealed that more than half of the surveyed nurses $(55.7 \%)$ were dissatisfied with the high proportion of administrative work. A greater administrative burden was on inpatient nurses regarding nursing documentation.

Another serious problem that is worth mentioning is the amount of work and the resulting time constraints. $30 \%$ of nurses in the outpatient wards often felt time pressures during the course of their work time and $52 \%$ of respondents stated very often. $38 \%$ of inpatient nurses perceived time constraints as often, with $30 \%$ as very often, and third place was occupied by $24 \%$ with the phrase "sometimes" (table 9). Based on this research, it was found that nurses working in inpatient wards feel greater levels of stress in terms of time constraints exerted on them, especially on the part of the waiting patients and because of the necessity to finish all the work in time. There is the possibility of unfinished work before the next shift for inpatient nurses.

The concept of the term "responsibility" has two meanings for which the nurse is responsible for and also according to her obligations. The legal responsibility for practicing nurses is specified by legislation - laws and moral responsibility have a specified code of ethics. The answers from the nurses in both wards were almost identically matched when asked about work-related stress due to a workload with greater work responsibilities. $47 \%$ of respondents in the inpatient wards felt a high degree of responsibility during their work and 30\% felt it as being often. For the outpatient wards, $43 \%$ of nurses see their profession as having a high burden of responsibility with $30 \%$ seeing it as being often high (table 10). In the research by Buriánek and Malina (5), they reported that the cause of the shortage of nurses in hospitals was due to workplace stress, precisely because of 
the workload with greater responsibilities.

Communication is a very important part of nursing care. For outpatient wards, communication with the patient and their family occasionally bothers $16 \%$ of nurses, $34 \%$ stated frequently and $43 \%$ of respondents admit that it is very often the conversations with patients burden their work. For inpatient wards, communications with respondents were expressed in this way: $32 \%$ of nurses are sometimes worried about communication with the patient and their family, $26 \%$ of nurses stated to having to formulate answers frequently and often (table 11). Communication skills by nurses fundamentally affect the relationship between the nurse, patient and their family.

Nurses who are communicative, helpful, kind and interested in the patient have a positive effect not only on the patient but also on their family. Cooperation with the family of the patient is very important because they are a source of important information about the patient. Conversely, the nurses provide information to the family regarding their necessary care towards the patient. Synergies between the nurse and the family significantly influence the nature and progress of the patient. In her research Bártlová focused on the most common causes of disputes between nurses and patients. Nurses working in outpatient wards often see the cause of conflicts is due to organizational difficulties stemming from the excessive number of patients and also the unjustified request for preferential examination. Inpatient nurses frequently reported health violations of their patients.

Treatment of the seriously ill and dying patients also causes distress for nurses. The largest group of respondents were from the inpatient wards where $57 \%$ feel distress very often when taking care of severely ill patients. $20 \%$ stated frequent and $14 \%$ stated occasional distress. For out- patient wards, $52 \%$ of nurses experience distress in the treatment of severely ill patients. 23\% stated frequent and $17 \%$ stated occasional distress. Only a small percentage from both wards will never feel the burden of care for the seriously ill and dying patients (table 12). It is widely known and confirmed by professional literature that the feelings of the individual in the course of their life is constantly changing and evolving. One of the most important characteristics of nurses in the care of the dying is equanimity including her coming to terms with their own mortality (7).

Both wards studied, almost unanimously agreed on the question as to what their opinion about their profession is. The largest group of nurses from the outpatient wards, $43 \%$, reported that they very often consider their work as challenging, $36 \%$ stated frequently challenging and 19\% stated occasionally challenging. $63 \%$ of inpatient ward respondents chose the answer most often challenging, $26 \%$ stated often challenging whilst $8 \%$ stated they occasionally see their profession as challenging, with possibly only $3 \%$ of respondents stating never challenging (table 13).

More than half of the respondents, $65 \%$ from outpatient wards and $85 \%$ from inpatient wards, feel a heavy burden in their jobs. A moderate load was stated by $30 \%$ of nurses from inpatient wards and $12 \%$ from outpatient ward. Only 5\% of respondents from inpatient wards and 3\% from outpatient wards stated that they do not perceive any burden (table 14).

One of the questions that was given to respondents was conceived as an open question. What time during the day did the nurses consider as the most stressful. Possible answers provided only benefited $2 / 3$ of respondents. Most inpatient ward nurses stated the morning part of their service and their morning rounds. The outpatient nurses perceived stress factors as having 
a waiting room full of impatient patients, improper requests for priority examination and frequently ringing phones.

\section{Improvement Recommendations}

1. Build an effective system of communication, not only between members of the multidisciplinary team, but also between nurse and patient.

2. Improve and continuously investigate working conditions.

3. Appeal to ensure an adequate number of staff at each site.

4. Support and extend supervision in health care.

5. Engage nurses in lifelong learning.

6. Clarify the competence of staff.

7. Improve communication skills.

8. Develop good interpersonal relationships.

9. Remember that people have personal lives, friends and hobbies.

10. Maintain good physical condition.

\section{Conclusion}

The main objective of the research was to describe the stress factors in the work of general nurses. Many factors contribute to inducing stress in the nursing profession. These factors may affect their physiological, emotional and behavioural levels. The results of the survey confirmed that the work of nurses is a very demanding profession in terms of the occurrence of a number of stress factors. The management of stress is a very topical issue for each of them. An important role is played by two motivations: the improvement in the combat of stress and helping others in their struggle with stress. General nurses carry out their work in a stressful environment and they also deal with patients who are also stressed. In their approach to stress, a nurse should keep in mind the above findings and relationships and use them purposefully to the benefit of both parties.

\section{Tables}

Table 1 What are the working relationships at your workplace?

\begin{tabular}{|c|c|c|c|c|}
\hline $\begin{array}{c}\text { Working } \\
\text { relations }\end{array}$ & inpatient & inpatient $\%$ & outpatient & outpatient $\%$ \\
\hline very bad & 4 & $6 \%$ & 6 & $8 \%$ \\
\hline bad & 14 & $23 \%$ & 33 & $45 \%$ \\
\hline good & 31 & $51 \%$ & 30 & $40 \%$ \\
\hline very good & 12 & $20 \%$ & 5 & $7 \%$ \\
\hline total & 61 & $100 \%$ & 74 & $100 \%$ \\
\hline
\end{tabular}

Table $\mathbf{2}$ What is your relationship with your superior?

\begin{tabular}{|c|c|c|c|c|}
\hline $\begin{array}{c}\text { Relationship } \\
\text { with your supe- } \\
\text { rior }\end{array}$ & inpatient & inpatient \% & outpatient & outpatient \% \\
\hline very bad & 7 & $12 \%$ & 7 & $10 \%$ \\
\hline bad & 13 & $21 \%$ & 35 & $47 \%$ \\
\hline
\end{tabular}




\begin{tabular}{|c|c|c|c|c|}
\hline good & 30 & $49 \%$ & 28 & $38 \%$ \\
\hline very good & 11 & $18 \%$ & 4 & $5 \%$ \\
\hline total & 61 & $100 \%$ & 74 & $100 \%$ \\
\hline
\end{tabular}

Table 3 Evaluate the cooperation with doctors during procedures and examinations.

\begin{tabular}{|c|c|c|c|c|}
\hline Cooperation & inpatient & inpatient $\%$ & outpatient & outpatient $\%$ \\
\hline very bad & 7 & $11 \%$ & 11 & $15 \%$ \\
\hline bad & 17 & $28 \%$ & 35 & $47 \%$ \\
\hline good & 27 & $45 \%$ & 20 & $27 \%$ \\
\hline very good & 10 & $16 \%$ & 8 & $11 \%$ \\
\hline total & 61 & $100 \%$ & 74 & $100 \%$ \\
\hline
\end{tabular}

Table 4 Do you receive praise and support from superiors?

\begin{tabular}{|c|c|c|c|c|}
\hline Praise & inpatient & inpatient $\%$ & outpatient & outpatient $\%$ \\
\hline never & 16 & $26 \%$ & 24 & $32 \%$ \\
\hline occasionally & 22 & $36 \%$ & 40 & $54 \%$ \\
\hline often & 14 & $23 \%$ & 8 & $11 \%$ \\
\hline very often & 9 & $15 \%$ & 2 & $3 \%$ \\
\hline total & 61 & $100 \%$ & 74 & $100 \%$ \\
\hline
\end{tabular}

Table 5 Do you have delegated tasks that do not fall within your competencies?

\begin{tabular}{|c|c|c|c|c|}
\hline Competence & inpatient & inpatient $\%$ & outpatient & outpatient $\%$ \\
\hline never & 2 & $3 \%$ & 1 & $2 \%$ \\
\hline occasionally & 7 & $11 \%$ & 4 & $5 \%$ \\
\hline often & 31 & $51 \%$ & 34 & $46 \%$ \\
\hline very often & 21 & $35 \%$ & 35 & $47 \%$ \\
\hline total & 61 & $100 \%$ & 74 & $100 \%$ \\
\hline
\end{tabular}


Table 6 Do you have the possibility of further vocational training?

\begin{tabular}{|c|c|c|c|c|}
\hline Training & inpatient & inpatient $\%$ & outpatient & outpatient $\%$ \\
\hline yes & 13 & $21 \%$ & 18 & $25 \%$ \\
\hline yes, but not offered & 33 & $54 \%$ & 48 & $65 \%$ \\
\hline no, but not offered & 14 & $23 \%$ & 4 & $5 \%$ \\
\hline no & 1 & $2 \%$ & 4 & $5 \%$ \\
\hline total & 61 & $100 \%$ & 74 & $100 \%$ \\
\hline
\end{tabular}

Table 7 Do you think that nurses have sufficient social prestige?

\begin{tabular}{|c|c|c|c|c|}
\hline Prestige & inpatient & inpatient $\%$ & outpatient & outpatient $\%$ \\
\hline yes & 2 & $4 \%$ & 4 & $5 \%$ \\
\hline no & 56 & $91 \%$ & 61 & $83 \%$ \\
\hline cannot judge & 3 & $5 \%$ & 9 & $12 \%$ \\
\hline total & 61 & $100 \%$ & 74 & $100 \%$ \\
\hline
\end{tabular}

Table 8 Are you burdened with the amount of administration?

\begin{tabular}{|c|c|c|c|c|}
\hline Administration & inpatient & inpatient $\%$ & outpatient & outpatient $\%$ \\
\hline never & 2 & $3 \%$ & 3 & $4 \%$ \\
\hline occasionally & 17 & $28 \%$ & 9 & $12 \%$ \\
\hline often & 23 & $38 \%$ & 18 & $24 \%$ \\
\hline very often & 19 & $31 \%$ & 44 & $60 \%$ \\
\hline total & 61 & $100 \%$ & 74 & $100 \%$ \\
\hline
\end{tabular}

Table 9 Do you feel time pressures while performing work tasks?

\begin{tabular}{|c|c|c|c|c|}
\hline Work tasks & inpatient & inpatient $\%$ & outpatient & outpatient $\%$ \\
\hline never & 3 & $5 \%$ & 6 & $8 \%$ \\
\hline occasionally & 8 & $13 \%$ & 18 & $24 \%$ \\
\hline often & 18 & $30 \%$ & 28 & $38 \%$ \\
\hline very often & 32 & $52 \%$ & 22 & $30 \%$ \\
\hline total & 61 & $100 \%$ & 74 & $100 \%$ \\
\hline
\end{tabular}


Table 10 Are you burdened with high responsibility in your work?

\begin{tabular}{|c|c|c|c|c|}
\hline Responsibility & inpatient & inpatient \% & outpatient & outpatient $\%$ \\
\hline never & 7 & $11 \%$ & 10 & $14 \%$ \\
\hline occasionally & 10 & $16 \%$ & 7 & $9 \%$ \\
\hline often & 18 & $30 \%$ & 22 & $30 \%$ \\
\hline very often & 26 & $43 \%$ & 35 & $47 \%$ \\
\hline total & 61 & $100 \%$ & 74 & $100 \%$ \\
\hline
\end{tabular}

Table 11 Are you burdened with communication with the patient and their family?

\begin{tabular}{|c|c|c|c|c|}
\hline Communication & inpatient & inpatient $\%$ & outpatient & outpatient $\%$ \\
\hline never & 4 & $7 \%$ & 12 & $16 \%$ \\
\hline occasionally & 10 & $16 \%$ & 24 & $32 \%$ \\
\hline often & 21 & $34 \%$ & 19 & $26 \%$ \\
\hline very often & 26 & $43 \%$ & 19 & $26 \%$ \\
\hline total & 61 & $100 \%$ & 74 & $100 \%$ \\
\hline
\end{tabular}

Table 12 Do you feel stress with the treatment of seriously ill and dying patients?

\begin{tabular}{|c|c|c|c|c|}
\hline Treatment & inpatient & inpatient $\%$ & outpatient & outpatient $\%$ \\
\hline never & 5 & $8 \%$ & 7 & $9 \%$ \\
\hline occasionally & 10 & $17 \%$ & 10 & $14 \%$ \\
\hline often & 32 & $52 \%$ & 15 & $20 \%$ \\
\hline very often & 14 & $23 \%$ & 42 & $57 \%$ \\
\hline total & 61 & $100 \%$ & 74 & $100 \%$ \\
\hline
\end{tabular}

Table 13 Do you consider your work as demanding?

\begin{tabular}{|c|c|c|c|c|}
\hline Work & inpatient & inpatient $\%$ & outpatient & outpatient $\%$ \\
\hline never & 1 & $2 \%$ & 2 & $3 \%$ \\
\hline occasionally & 12 & $19 \%$ & 6 & $8 \%$ \\
\hline often & 22 & $36 \%$ & 19 & $26 \%$ \\
\hline very often & 26 & $43 \%$ & 47 & $63 \%$ \\
\hline total & 61 & $100 \%$ & 74 & $100 \%$ \\
\hline
\end{tabular}


Table 14 What level of stress do you feel when performing your job?

\begin{tabular}{|c|c|c|c|c|}
\hline Level & inpatient & inpatient $\%$ & outpatient & outpatient $\%$ \\
\hline none & 3 & $5 \%$ & 2 & $3 \%$ \\
\hline mild & 18 & $30 \%$ & 9 & $12 \%$ \\
\hline high & 40 & $65 \%$ & 63 & $85 \%$ \\
\hline total & 61 & $100 \%$ & 74 & $100 \%$ \\
\hline
\end{tabular}

\section{References}

1. Jankechová M., Kunayová A. (2011): The working conditions of nurses in nursing clinical praxis. In Proceedings of the international conference Jihlava's medical days 2011. First year. Jihlava: College of Polytechnics, pp. 281-291. ISBN 978-80-8703537-5.

2. Jankechová M., Gajdošíková E. (2013): Investigation of the risk factors affecting the health of nurses. In Proceedings of the international conference Jihlava's medical days 2013. III. year. New trends in nursing and midwifery. Jihlava: College of Polytechnics, pp. 291-299. ISBN 978-80-87035-726.

3. Bártlová S. (2007): Industrial relations and competencies of nurses in Czech Republic. Nurse, vol. 17, no. 3, pp. 14-17. ISSN 12100404.
4. Bártlová S., Hajduchová H. (2010): Transfer of competencies between the doctor and nurse. Contact, vol. 12, no. 1, pp. 20-33. ISSN 1212 to 4117.

5. Buriánek J., Malina A. (2009): Job satisfaction of nurses. Healthcare in Czech Republic, vol. XII, no. 3, pp. 82-89. ISSN 12136050.

6. Křivohlavý J., Pečenková J. (2004): Mental hygiene of nurses. Praha: Grada, 2004. 80 pp. ISBN 80-247-0784-5.

7. Svatošová M. (2003): Hospice and art accompany. 5th edition. Praha: Ecco homo, 150 pp. ISBN 80-902049-4-5.

8. Škrla P., Škrlová M. (2003): Creative nursing management. Prague: Advent - Orion, 477 pp. ISBN 80-7172-841-1.

9. Vévoda J. et al. (2013): The motivation and job satisfaction of nurses in health care. Prague: Grada, 160 pp. ISBN 978-80-2474732-3. 
